\title{
Maternal-by-environment but not genotype-by-environment interactions in a fish without parental care
}

\author{
Regina Vega-Trejo ${ }^{1} \cdot$ Megan L. Head ${ }^{1} \cdot$ Michael D. Jennions $^{1,2} \cdot$ Loeske E.B. Kruuk $^{1}$
}

Received: 27 June 2017 / Revised: 27 September 2017 / Accepted: 30 October 2017 / Published online: 11 December 2017

(c) The Genetics Society 2018

\begin{abstract}
The impact of environmental conditions on the expression of genetic variance and on maternal effects variance remains an important question in evolutionary quantitative genetics. We investigate here the effects of early environment on variation in seven adult life history, morphological, and secondary sexual traits (including sperm characteristics) in a viviparous poeciliid fish, the mosquitofish Gambusia holbrooki. Specifically, we manipulated food availability during early development and then assessed additive genetic and maternal effects contributions to the overall phenotypic variance in adults. We found higher heritability for female than male traits, but maternal effects variance for traits in both sexes. An interaction between maternal effects variance and rearing environment affected two adult traits (female age at maturity and male size at maturity), but there was no evidence of trade-offs in maternal effects across environments. Our results illustrate (i) the potential for prenatal maternal effects to interact with offspring environment during development, potentially affecting traits through to adulthood and (ii) that genotype-by-environment interactions might be overestimated if maternal-by-environment interactions are not accounted for, similar to heritability being overestimated if maternal effects are ignored. We also discuss the potential for dominance genetic variance to contribute to the estimate of maternal effects variance.
\end{abstract}

\section{Introduction}

A central tenet of evolutionary ecology is the expectation that environmental conditions affect evolutionary processes. Evolutionary responses to selection on a trait require the trait to have a genetic basis, so an understanding of the genetic components of phenotypic variation is required to predict evolutionary dynamics (McAdam et al. 2002; Mousseau and Fox 1998; Noble et al. 2014). Quantitative traits are likely to be determined by a large number of genes each with a small effect (Falconer and Mackay 1996; Lynch

Electronic supplementary material The online version of this article (https://doi.org/10.1038/s41437-017-0029-y) contains supplementary material, which is available to authorized users.

Regina Vega-Trejo

reginavegatrejo@gmail.com

1 Division of Ecology and Evolution, Research School of Biology, The Australian National University, Acton, Canberra, ACT 2601, Australia

2 Wissenschaftkolleg zu Berlin, Wallotstraße 19, 14193 Berlin, Germany and Walsh 1998), and the genetic basis of phenotypic variation - or heritability - of a trait can be quantified indirectly from similarities in trait values between relatives (Falconer and Mackay 1996; Lynch and Walsh 1998). However, variation in the environmental conditions individuals experience can play an important role in the process of identifying the genetic components of trait variation. First, similarities between relatives might be due to shared environmental effects, such as maternal effects, which therefore need to be accounted for to generate accurate estimates of heritability (Kruuk and Hadfield 2007; Wolf and Wade 2016). Second, variation in environmental conditions can affect the expression of genetic variance (Rowiński and Rogell 2017; Sgrò and Hoffmann 2004). Third, variation in environmental conditions is also likely to affect the expression of other components of variance, including maternal effects (Mousseau and Fox 1998; Uller et al. 2013).

Changes in the observed genetic variance underlying phenotypic traits in different environmental conditions are known as genotype-by-environment interactions $(\mathrm{G} \times \mathrm{E}$; Charmantier and Garant 2005; Hoffmann and Merila 1999; Rowiński and Rogell 2017; Wood and Brodie 2015). There 
is abundant evidence from laboratory studies on animals of $\mathrm{G} \times \mathrm{E}$ for a range of traits, based on phenotypic responses to manipulation of environmental conditions such as food availability, temperature, and pathogen levels (e.g. Evans et al. 2015; Ferguson and Read 2002; Vieira et al. 2000). Plant studies also frequently report evidence for $\mathrm{G} \times \mathrm{E}$ (Des Marais et al. 2013): plants of different genotypes or from different populations show marked variation in their phenotypic responses to key environmental variables (e.g. de Leon et al. 2016; Donohue et al. 2000). Understanding whether the performance of genotypes is correlated across environments is critical to determine the extent to which environmental variation might maintain genetic variance (Barton and Turelli 1989; Johnson and Barton 2005): do genotypes that are successful in one environment also do well in another, or are there 'trade-offs' across environments (Kruuk et al. 2008)? Here, we consider how substantial these aspects of $\mathrm{G} \times \mathrm{E}$ might be relative to other determinants of phenotypic variation in key life history and related traits.

An individual's phenotype is shaped by multiple factors in addition to its genotype, one of which is the effect its mother has on it (Pick et al. 2016; Wolf and Wade 2009). 'Maternal effects' occur when a mother's phenotype affects that of her offspring over and above that attributable to the genes it inherits from her (Mousseau and Fox 1998; Räsänen and Kruuk 2007). This might involve pre-natal and/or post-natal effects (Lock et al. 2007; Pick et al. 2016; Wolf et al. 2011). The influence of maternal effects on offspring phenotype is often highly dependent on the mother's own environment. For example, mothers experiencing good environmental conditions may produce larger offspring, breed sooner, or provide more food and greater parental care (Marshall and Uller 2007; Mousseau and Fox 1998; Reznick and Yang 1993). In general, the most obvious mechanisms driving variation in maternal effects point towards environmental factors that alter the mother's phenotype (e.g. mothers in poor condition provide less milk; Trivers 1974). If mothers differ in how they respond to environmental variation, this plasticity can be thought of as "maternal-by-environment interactions" or $\mathrm{M} \times \mathrm{E}$, akin to genotype-by-environment interactions. Maternal-byenvironment $(\mathrm{M} \times \mathrm{E})$ interactions have been less thoroughly investigated than $\mathrm{G} \times \mathrm{E}$ in the context of variance component analyses (though see for example Chirgwin et al. 2017; Laugen et al. 2005), so in general we have little idea whether 'good' environments generally amplify or depress any differences among mothers, nor of the potential for trade-offs across environments whereby mothers that are superior in one environment are inferior in another (i.e. negative cross-environment maternal effect correlations).

The timing of environmental variation may also drive biologically important effects on trait expression. Maternal effects plasticity is typically investigated in the context of variation in the mother's environment. $\mathrm{M} \times \mathrm{E}$ could, however, equally plausibly be generated by maternal effects differing in interactions with the offspring's environment. In many cases, the two sources of environmental variation impacting on maternal effects are indistinguishable. For example, more stressful environmental conditions reduce variation among mothers in maternal effects for offspring birth weight in wild Soay sheep (Wilson et al. 2005), but it is not possible to determine to what extent this is due to effects of the environment on mothers or on their lambs. We therefore know less about how maternal effects vary 'downstream' due to variation in the offspring's environment. More specifically, are there predictable differences between mothers in how their offspring respond to changes in environmental conditions? In particular, do mothers vary in how much their offspring are able to withstand environmental stress? Addressing this aspect of $\mathrm{M} \times \mathrm{E}$ requires focusing on changes in the offspring's environment once maternal care has ceased.

Analysis of maternal-by-environment interactions may also be important for methodological reasons. Maternal effects typically make relatives (i.e. siblings) look more similar than they would otherwise. They can therefore be difficult to disentangle from additive genetic effects, which are typically estimated from the degree of similarity between relatives. Maternal effects have the potential to inflate estimates of genetic variance unless properly modelled, and there is general acceptance of the need to control for maternal effects when estimating the heritability of a trait (Kruuk and Hadfield 2007; McAdam et al. 2014). However, less attention has been paid to the fact that the same issue applies to tests for $\mathrm{G} \times \mathrm{E}$ interactions: just as the occurrence of maternal effects can inflate estimates of additive genetic variance and heritability, the occurrence of $\mathrm{M} \times \mathrm{E}$ should presumably inflate estimates of $\mathrm{G} \times \mathrm{E}$. To our knowledge, this possibility remains untested. It implies that, in addition to the fundamental biological question of whether offspring of different mothers are differentially affected by environmental stress due to maternal effects, quantifying $\mathrm{M} \times \mathrm{E}$ may be a critical component of analysis of $\mathrm{G} \times \mathrm{E}$.

General conclusions about the prevalence of $\mathrm{G} \times \mathrm{E}$ and $\mathrm{M} \times \mathrm{E}$ in a system also require assessment of different traits. Different types of traits typically show different patterns of heritability, of maternal effects and, presumably, of respective interactions with the environment. Traits that are closely associated with fitness often show lower heritability than more weakly-selected traits (Houle 1992; Postma 2014; Roff and Mousseau 1987). For instance, life history traits, such as fecundity and viability, are under strong directional selection and show lower heritability than morphological and physiological traits (Kruuk et al. 2000; Roff 
and Mousseau 1987). Sexually selected traits may also show different patterns of variation, alongside differences between the sexes in their genetic architecture (Jia et al. 2000; Parker and Garant 2004). However, comparatively little is known about the relative magnitude of $\mathrm{G} \times \mathrm{E}$, let alone $\mathrm{M} \times \mathrm{E}$, for different types of traits.

Here, we experimentally manipulated a critical aspect of the environment experienced by offspring during their early development (food availability), to assess the relative contribution of additive genetic versus maternal effects on phenotypic variance, as well as the extent to which each contribution was influenced by the environmental stress of food restriction. We used a multigenerational breeding design of a laboratory population of mosquitofish (Gambusia holbrooki) to test for $\mathrm{G} \times \mathrm{E}$ and $\mathrm{M} \times \mathrm{E}$ interactions in seven adult phenotypic traits: size and age at maturity for both males and females, and three sexually selected male traits, namely, relative genital size, sperm number, and sperm velocity. We considered this range of phenotypic traits in order to investigate the importance of different sources of variance for multiple aspects of adult phenotypes. In many taxa, size and age at maturity are key life history traits often linked to fitness (Roff 1992). Likewise, some sperm traits are strongly positively associated with fitness (Parker and Pizzari 2010), although this is not always the case (e.g. Simmons et al. 2003). We already have clear evidence for maternal effects on growth and development rates that persist until sexual maturity in G. holbrooki (Kruuk et al. 2015). Here, we assessed the potential for environmental stress (food restriction) during offspring development to generate both $\mathrm{G} \times \mathrm{E}$ and $\mathrm{M} \times \mathrm{E}$. Gambusia holbrooki is a live-bearing fish lacking post-natal parental care, so all maternal effects must be mediated by events prior to birth. Our experiment therefore constitutes a test for interactions between pre-natal maternal effects (M) and post-natal (i.e. offspring alone) environmental conditions (E). We asked (1) What is the relative importance of additive genetic vs maternal effects in contributing to phenotypic trait variance in each sex? (2) Do these effects interact with the environmental conditions experienced by the offspring? And if so, are there (i) consistent differences in the levels of additive genetic and maternal effects variance between good and poor environments and (ii) tradeoffs across environments in either genetic or maternal effects?

\section{Methods}

\section{Study species}

Gambusia holbrooki, a species of viviparous poeciliid fish, is endemic to North America but now introduced worldwide
(Pyke 2005). G. holbrooki have internal fertilisation, are sexually dimorphic, and males transfer sperm by a modified anal fin ('gonopodium') that acts as an intromittent organ (Pyke 2005). There is substantial variation in female adult size, which is strongly positively correlated with fecundity (Bisazza et al. 1989; Callander et al. 2012). Male size also varies considerably, despite their growth ceasing at maturation. Small males have greater manoeuvrability, which seems to increase their propensity to sneak copulations (Pilastro et al. 1997), while large males are socially dominant and might transfer more sperm per copulation because they have greater sperm reserves (Bisazza and Marin 1991; O'Dea et al. 2014). Selection on male size in this species is, in summary, unclear. Recent studies in our lab of free-swimming fish have found negative selection (favouring smaller males, Head et al. 2017), no selection (Vega-Trejo et al. 2017), and positive selection (favouring larger males, Booksmythe et al. 2016). Age at maturation in both sexes is highly variable (see Livingston et al. 2014; Pyke 2005; Vega-Trejo et al. 2016a). Greater relative gonopodium size is also linked to increased reproductive success (Head et al. 2017; Vega-Trejo et al. 2017; but see Booksmythe et al. 2016). Finally, sperm velocity declines with age (Vega-Trejo et al. 2016b), and sperm number has been shown to be condition-dependent and positively related to body length (O'Dea et al. 2014).

\section{Experimental design}

Our analyses are based on measurements of seven phenotypic traits from laboratory reared G. holbrooki in which we varied the level of food an individual received during development. Our multi-generation breeding design also involved the comparison of fish with different levels of inbreeding, as part of a separate investigation into the effects of inbreeding (Vega-Trejo et al. 2016a; Vega-Trejo et al. 2017). The base stock $\left(F_{0}\right)$ population consisted of offspring from 151 gravid wild-caught females collected in Canberra, Australia. $F_{0}$ fish were kept in single-sex tanks under a $14: 10$ photoperiod at $28^{\circ} \mathrm{C}$, and fed ad libitum with Artemia nauplii and commercial flakes (Fig. 1). Once they were mature, we randomly paired fish from this base stock to create full-sib families $\left(F_{1}\right)$. Fish from these full-sib families were then used to create an $\mathrm{F}_{2}$ generation consisting of 58 outbred families (with unrelated parents) and 58 inbred families (with full-sib parents; $f=0.25$; Fig. 1). To do this, we used 29 pairs of full-sib families (e.g. A and B), which we refer to as "blocks". Within each block, one male from family A and one from family B respectively were paired to females (between 1 and 4) from the other family, to create outbred full-sibs/half-sibs (AB and $\mathrm{BA}$ ); and one male from each family was paired to his full-sib sisters (again, 1-4 females per male) to create inbred full-sibs/half- 


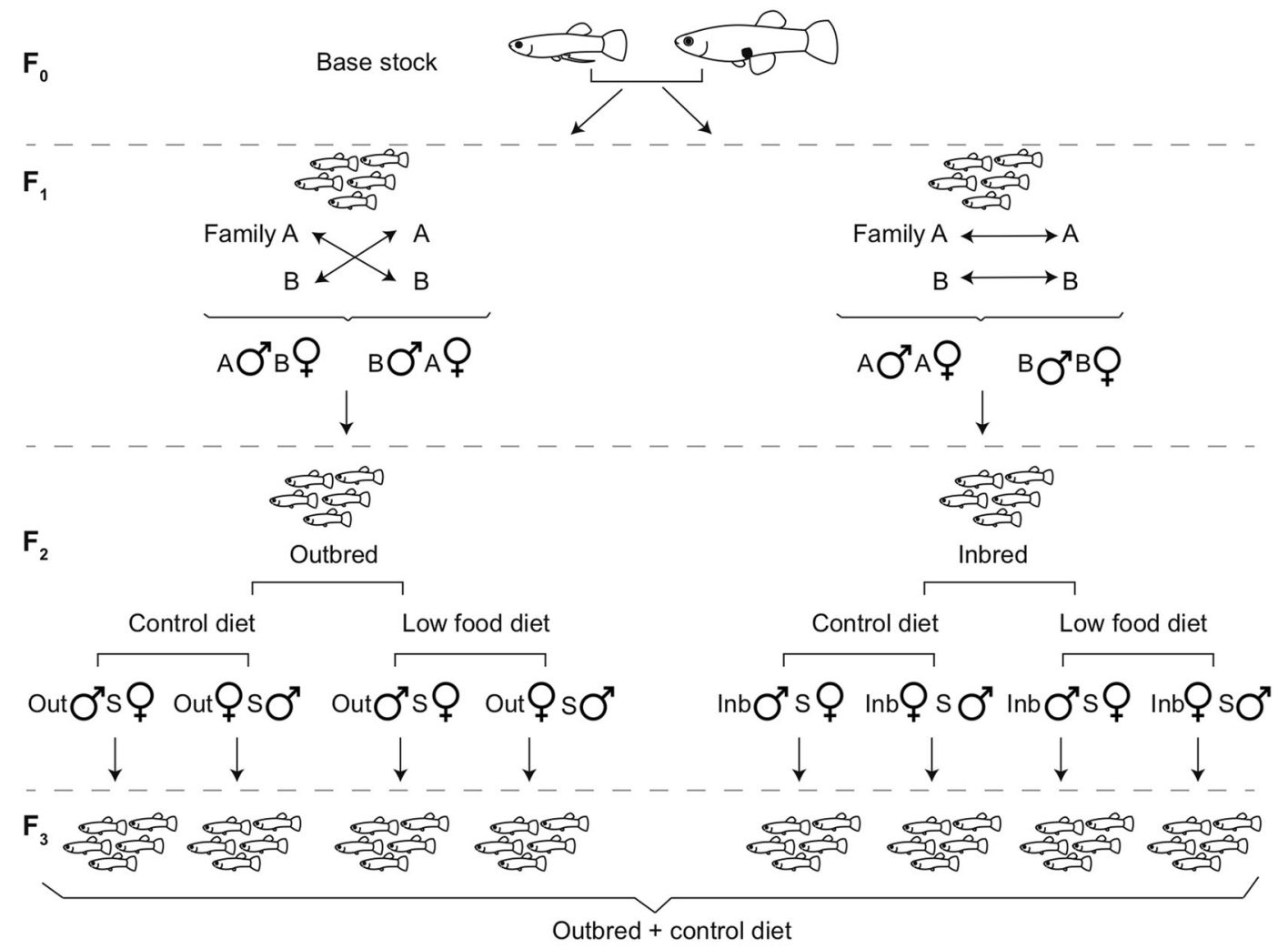

Fig. 1 Schematic of the experimental design. $\mathrm{S}=$ stock fish. $\mathrm{F}_{0}$ stock males and females were paired to create $F_{1}$ full-sib families (e.g. A and B). We set up 1-4 females per cross-type to create $F_{2}$ outbred (AB, BA -Out) and inbred (AA, BB-Inb) fish. These fish were reared on

sibs (AA and BB). The same number of females contributed to each of the four cross-types within a block to generate a mix of inbred and outbred half-sib and full-sib families. We then reared a maximum of 10 offspring per female (i.e. fullsib family). See Vega-Trejo et al. (2015) and Vega-Trejo et al. (2016a) for a fuller methodological description.

The food manipulation experiment was conducted on the $\mathrm{F}_{2}$ generation (described below). In the $\mathrm{F}_{2}$ generation, half of the offspring in each family were raised on a 'control' diet, whereas the other half experienced a 'low food' diet early in life (Fig. 1). Fish on the control diet were fed ad libitum with Artemia nauplii twice a day from birth until the end of the experiment. Fish on the low diet were fed the control diet until they were one week old, and were then fed $3 \mathrm{mg}$ of Artemia nauplii once every other day (i.e. $<25 \%$ of the control food intake) for 21 days, after which they were returned to the control diet. Fish almost totally suppressed growth while on the low food diet (Livingston et al. 2014; Vega-Trejo et al. 2016a). For completeness, we also included in our analyses measurements on the $\mathrm{F}_{3}$ generation. The $\mathrm{F}_{3}$ generation was created by pairing each $\mathrm{F}_{2}$ female with a stock male, and by using sperm from $\mathrm{F}_{2}$ males to artificially inseminate stock females (Fig. 1). Thus, all $\mathrm{F}_{1}$ and $F_{3}$ fish were outbred and raised on a control diet, either a control or a low food diet early in life. $\mathrm{F}_{2}$ females from each treatment were paired with a stock (outbred) male to create $F_{3}$ offspring. $F_{2}$ males from each treatment artificially inseminated stock (outbred) females to create $F_{3}$ offspring. $F_{3}$ offspring were classified as outbred and control diet

whereas $\mathrm{F}_{2}$ fish were both outbred or inbred, and raised on either a control or restricted diet. Offspring of all generations were transferred to individual tanks at birth to eliminate the potential for post-natal shared environment effects.

\section{Measurements of phenotypic traits}

For individuals of generations $\mathrm{F}_{2}$ and $\mathrm{F}_{3}$, we measured seven adult traits. Table 1 lists the traits measured, with sample sizes and summary statistics. To determine the timing of sexual maturity, we inspected all tanks three times a week. Females were considered to be mature when yolked eggs were evident in the abdomen (Stearns 1983). Males were considered to be mature when their gonopodium was translucent, with a spine visible at the tip (Stearns 1983; Zulian et al. 1993).

To measure morphological traits, we anaesthetized fish by submersion in ice-cold water for a few seconds to reduce movement. The fish were then photographed alongside a microscopic ruler $(0.1 \mathrm{~mm}$ gradation). We used Image $\mathbf{J}$ software (Abramoff et al. 2004) to measure: body length at maturity (snout tip to base of caudal fin, in $\mathrm{mm}$ ) for both males and females, and male gonopodium length (apical tip to base, in $\mathrm{mm}$ ). We then calculated relative gonopodium 


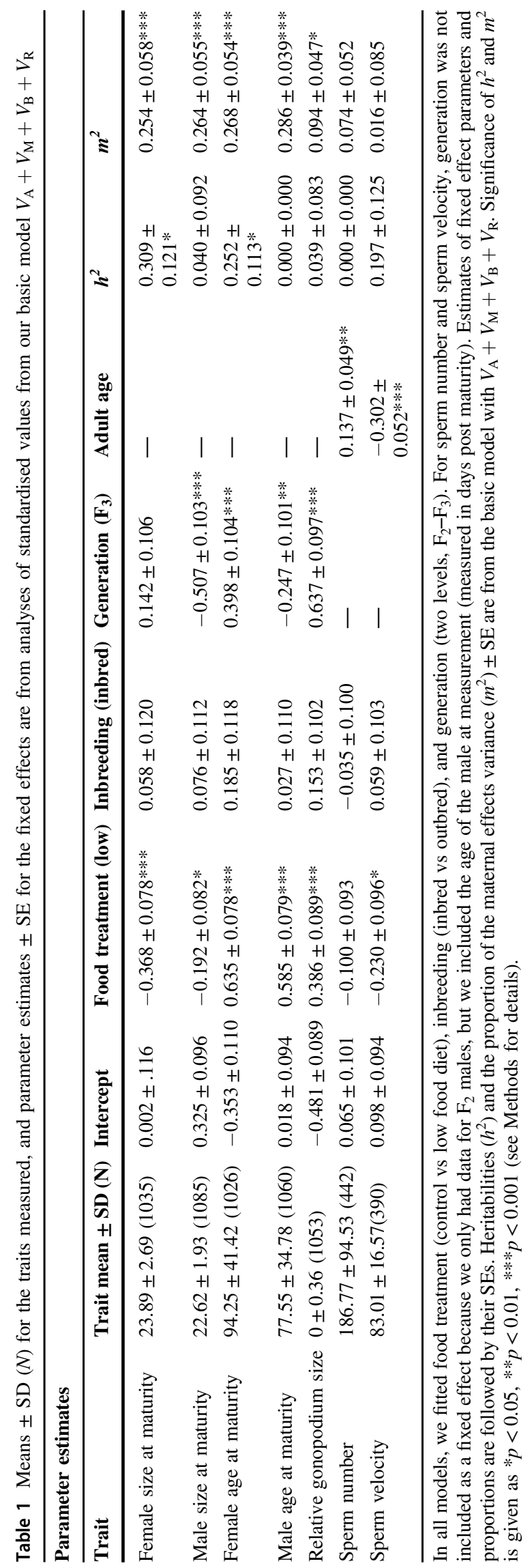

size for males as the residuals from a linear regression of (log) gonopodium length on $(\log )$ standard length (Horth et al. 2010; Vega-Trejo et al. 2017).

We measured two sperm traits in the $F_{2}$ generation: sperm number and sperm velocity. Details on the extraction of ejaculates and the samples are given in the Supplementary Information. In brief, males were anaesthetized in icecold water, placed on a glass slide and their gonopodium was swung forward. We then applied gentle pressure to the abdomen to eject all of the available sperm. We counted the sperm and measured sperm velocity. Afterwards, each male was returned to his individual tank. All inspections for maturity and measurements of traits were made blind to food treatment, inbreeding status, and family identity.

\section{Statistical analyses}

We quantified components of variance in the phenotypic traits using an 'animal model', a form of mixed model that uses pedigree information to assess covariance between relatives (Wilson et al. 2010), fitted using ASReml-R (Butler et al. 2009). All models contained random effects of an additive genetic effect (with covariance structure defined by relatedness between individuals, as determined by the breeding design's pedigree, and associated additive genetic variance component $V_{\mathrm{A}}$ ), a maternal effect (grouping individuals by mother, with associated maternal effects variance component $V_{\mathrm{M}}$; Kruuk and Hadfield 2007), a block component (with variance component $V_{\mathrm{B}}$, defined above), and residual effect (with associated variance component $V_{\mathrm{R}}$ ).

The animal model estimates the additive genetic variance underlying a trait's variance based on the similarity between multiple types of relatives; here relatedness, was defined by our four-generation pedigree $\left(\mathrm{F}_{0}-\mathrm{F}_{3}\right)$. The estimate of the maternal effects variance $V_{\mathrm{M}}$ was determined by the increased similarity between offspring of the same mother, beyond that due to additive (direct) genetic effects (Kruuk and Hadfield 2007). This value will necessarily encompass both maternal environment effects and maternal genetic effects (i.e. effects of the mother's genotype on her offspring, over and above the direct effects of the genes they inherit from her); we do not attempt to separate them. Offspring were reared separately from birth onward (see above), so there is little potential for post-natal common environment effects to inflate estimates of maternal effects. Offspring of the same mother were, however, always fullsiblings, so there is the potential for the estimate of $V_{\mathrm{M}}$ to be inflated by dominance genetic variance (Falconer and Mackay 1996). We make the standard assumption that dominance variance is small compared to additive genetic variance (e.g. Hill et al. 2008; Zhu et al. 2015), and hence 
that any impact is also small, but we return to this point in the Discussion.

All traits were standardised to unit variance and zerocentred prior to analysis, and we analysed the data separately for males and females. In all models, we fitted food treatment (control vs low food diet), inbreeding (inbred vs outbred), and generation (two levels, as phenotypic data were only available for $F_{2}$ and $F_{3}$ ) as fixed factors. For sperm number and velocity, generation was not fitted because we only measured $\mathrm{F}_{2}$ males. However, for the sperm traits we included fixed effects of male age (range 19-125 days post maturity) as age influences sperm number and velocity (Vega-Trejo et al. 2016b). The parameter estimates for the fixed effects in a model with only $V_{\mathrm{A}}, V_{\mathrm{M}}$, $V_{\mathrm{B}}$, and $V_{\mathrm{R}}$ (see details below) are in Table 1. Parameter estimates for the effects of food treatment are shown in Fig. S1.

\section{Univariate models of interactions with environmental conditions}

We first fitted univariate models for each of the seven traits to explore the extent of interactions of both the additive genetic variance and maternal effects variance with environmental conditions (i.e. food treatment). We started with Model 1, a 'null' model with only fixed effects (as described above: food, inbreeding, and generation), block as a random effect, and a residual random effect. We then fitted: Model 2 , which included variance due to additive genetic effects $\left(V_{\mathrm{A}}\right)$; Model 3, a model containing just the maternal effects variance $\left(V_{\mathrm{M}}\right)$; and Model 4 , a model that included both components of variance $\left(V_{\mathrm{A}}+V_{\mathrm{M}}\right)$. We call this the 'basic model'. We report the trait's heritability $\left(V_{\mathrm{A}} /\left(V_{\mathrm{A}}+V_{\mathrm{M}}+\right.\right.$ $\left.\left.V_{\mathrm{B}}+V_{\mathrm{R}}\right)\right)$ and maternal effects proportion $\left(V_{\mathrm{M}} /\left(V_{\mathrm{A}}+V_{\mathrm{M}}+\right.\right.$ $\left.V_{\mathrm{B}}+V_{\mathrm{R}}\right)$ ) from the basic model in Table 1 .

We then investigated whether the variance components changed between the two food treatments (i.e. Genotype $\times$ Environment or Maternal effect $\times$ Environment) by testing for either a $V_{\mathrm{A}} \times$ Food or $V_{\mathrm{M}} \times$ Food interaction. To do so, we first included the interactions between each variance component and the food treatment in models with only one main variance component (i.e. Model 5: $V_{\mathrm{A}}+V_{\mathrm{A}} \times$ Food; and Model 6: $V_{\mathrm{M}}+V_{\mathrm{M}} \times$ Food), and then in models which included both main terms (i.e. Model 7: $V_{\mathrm{A}}+V_{\mathrm{M}}+V_{\mathrm{A}} \times$ Food; and Model 8: $V_{\mathrm{A}}+V_{\mathrm{M}}+V_{\mathrm{M}} \times$ Food). Finally, we ran a model with all main terms and interactions (Model 9: $V_{\mathrm{A}}+V_{\mathrm{M}}+V_{\mathrm{A}} \times$ Food $+V_{\mathrm{M}} \times$ Food $)$.

\section{Model comparison}

Because we wished to compare several models, many of which were not nested, we used a model comparison approach based on the Akaike Information Criterion AIC
(Burnham and Anderson 2002; see Saastamoinen et al. 2013 for a similar model comparison of different animal models). We calculated $\mathrm{AIC}$ as $-2 \log (L)+2 \mathrm{~K}$, where $\log$ $(L)$ was the model's log likelihood and $\mathrm{K}$ the number of parameters estimated. We only considered the number of parameters associated with estimating variance in the different random effects (other than the residual and block variance estimates), given that the fixed effects were the same in all models for a given trait. Thus, $\mathrm{K}$ ranged from 0 (null model: model with only fixed effects and one random effect of block) to 4 (final model with $V_{\mathrm{A}}, V_{\mathrm{M}}, V_{\mathrm{A}} \times$ Food and $V_{\mathrm{M}} \times$ Food). Akaike weights $w$ for each model $i$ were calculated as $w_{i}=\exp \left(\Delta \mathrm{AIC}_{i}\right) / \sum \exp (\Delta \mathrm{AIC})$, where $\Delta \mathrm{AIC}$ is the difference in AIC between model $i$ and the model with the lowest AIC (the top model for that trait). Models ranked within two AIC units of the top model were considered to be 'reasonable candidate' models providing indistinguishable levels of support (Burnham and Anderson 2002). The number of reasonable models ranged from one to four across the different traits.

The informational approach outlined above allowed us to compare differences between models for each trait. We then determined the significance of the interaction parameter estimates in the top model. To do this, we ran likelihood ratio tests (LRT) comparing the top model to one without that parameter. The test statistics and $P$-values are given in the text of the Results. We also tested for the significance of $V_{\mathrm{A}}$ and $V_{\mathrm{M}}$ by LRTs by respectively dropping those terms from the basic model $\left(V_{\mathrm{A}}+V_{\mathrm{M}}+V_{\mathrm{B}}+V_{\mathrm{R}}\right)$. The $P$-values from these LRTs are shown in Table 1 adjacent to the heritability (i.e. for $V_{\mathrm{A}}$ ) and to the proportion of maternal effects variance (i.e. for $V_{\mathrm{M}}$ ).

For each trait, we report the variance components for the reasonable candidate models in the main Results, and for all nine models in the Supplementary Information. However, given that there might be some level of support for multiple models, we also provide model-averaged parameter estimates (Burnham and Anderson 2002). For each trait, we model averaged the estimates of the different variance components across our 9 models, where the model-averaged variance component $V^{*}$ was calculated by weighting $V_{i}$, the variance estimate of model $i$ with the weights $w_{\mathrm{i}}$ as calculated above, such that $V^{*}=\sum\left(V_{i} \times w_{i}\right)$. We also estimated model-averaged standard error as $\mathrm{SE}^{*}=\sum\left[w_{i} \times \sqrt{ }\left(\mathrm{SE}_{i}^{2}+\right.\right.$ $\left.\left(V_{i}-V^{*}\right)^{2}\right)$ ] (Burnham and Anderson 2002).

\section{Bivariate models across environments}

We found evidence for interactions between food treatment and variance components for both female age at maturity and male size at maturity (see Results). We therefore fitted bivariate models to estimate the variance due to additive genetic effects and maternal effects within each food 
treatment, by splitting each trait by treatment to define two new "sub-traits". These models contained inbreeding level and generation as fixed effects as above, and maternal and additive genetic effects as random effects in order to generate environment-specific estimates of the variance components in each trait. Block was also included as a random effect for female age at maturity, but was not fitted for male size at maturity given a lack of convergence (note: for other traits, fitting block made little difference to the parameter estimates). Each model also contained estimates of the covariance across environments in additive genetic, maternal effect, and (for female age) block effects. We also ran a model with additive genetic effects only to compare our estimates of $V_{\mathrm{A}}$ when maternal effects were ignored.

\section{Results}

Almost all traits were affected by the food treatment during development, but there was no effect of inbreeding on trait means (Table 1). However, there were marked differences among traits as to which of the different combinations of variance components produced the best model. Table 2 shows the reasonable candidate models ( $<2$ AIC units from the top model) for each trait with their corresponding variance estimates, and also the model-averaged variance estimates averaged across all models. For the corresponding details of all 9 models for each trait, see Table S1.

We found evidence of additive genetic and maternal effects variance for almost all traits. However, the interaction with food treatment varied substantially between traits. Below we present results for each trait in turn.

\section{Female size at maturity}

Females on the low food treatment were slightly smaller at maturity than those on control diets (Table 1; Fig. S1). For the 'basic' model with just $V_{\mathrm{A}}+V_{\mathrm{M}}$, we found substantial heritability and maternal effects variance (Table 1). Comparing all models, both of the 'reasonable candidate' models contained variance due to additive genetic effects and maternal effects, with the top model containing only $V_{\mathrm{A}}+$ $V_{\mathrm{M}}$ (i.e. the 'basic' model as defined above; Table 1). Although $V_{\mathrm{M}} \times$ Food appeared in the second-ranked model, overall there was little indication of support for this interaction (LRT: $X^{2}{ }_{(1)}=0.546, P=0.761$; Table 2); this model fits the characteristics of a 'hitch-hiking' model, where an additional term generates a very slight improvement in model fit and so falls within 2 AIC units of the top model (Arnold 2010; Symonds and Moussalli 2011). Similarly, there was no support for a $V_{\mathrm{A}} \times$ Food interaction (LRT: $X^{2}$ (1) $<0.001, P=1$; Table S1).

\section{Male size at maturity}

Males on the low food treatment were also smaller at maturity (Table 1; Fig. S1). The estimates of heritability and maternal effects proportions from the basic $V_{\mathrm{A}}+V_{\mathrm{M}}$ model showed little heritability but substantial maternal effects variance in male size (Table 1). Model comparison indicated strong support for a $V_{\mathrm{M}} \times$ Food interaction as the term appeared in both of the two reasonable candidate models (Table 2), and the top model contained both $V_{\mathrm{M}}$ and a significant $V_{\mathrm{M}} \times$ Food interaction $\left(\mathrm{LRT}: X^{2}{ }_{(1)}=18.205, P\right.$ $<0.001)$. We found little support for a $V_{\mathrm{A}} \times$ Food interaction (Table S1). We fitted a bivariate model of environmentspecific traits to estimate the variance components for each food treatment. There was significant variance in maternal effects in the control environment but not in the low food environment (Fig. 2a). There was also a negligible covariance (negative) of the maternal effects across environments, most likely because of the lack of variation among mothers in the low food environment (Fig. 2a, Table 3).

\section{Female age at maturity}

Females in the low food treatment took on average $21 \%$ longer to mature (Table 1; Fig. S1). Similar to female size at maturity, the basic $V_{\mathrm{A}}+V_{\mathrm{M}}$ model indicated substantial heritability and maternal effects for female age at maturity. In the model comparison, the only reasonable candidate model was that containing $V_{\mathrm{A}}$ and $V_{\mathrm{M}}$ and a $V_{\mathrm{M}} \times$ Food interaction (LRT for $V_{\mathrm{M}} \times$ Food: $X_{(1)}^{2}=6.449, P=0.039$; Table 2). When we considered female age at maturity in the two environments separately, we found much higher variance in maternal effects in the low food environment than in the control environment, and also a positive covariance of maternal effects across the two environments (Fig. 2b, Table 3).

\section{Male age at maturity}

Males in the low food treatment took on average 38\% longer to mature than those on the control diet (Table 1, Fig. S1). As with male size at maturity, the basic model with only $V_{\mathrm{A}}$ $+V_{\mathrm{M}}$ showed little heritability but substantial maternal effects variance (Table 1). The reasonable candidate model set contained a top model with $V_{\mathrm{M}}$ only and another with $V_{\mathrm{M}}$ and a $V_{\mathrm{M}} \times$ Food interaction. However, similar to female size, the second model was consistent with a hitch-hiking model because there was little support for the $V_{\mathrm{M}} \times$ Food interaction (LRT: $X^{2}{ }_{(1)}=0.987, P=0.611$; Table 2).

\section{Relative gonopodium size}

Males in the low food environment had relatively longer gonopodia on average (Table 1, Fig. S1). In the basic model 


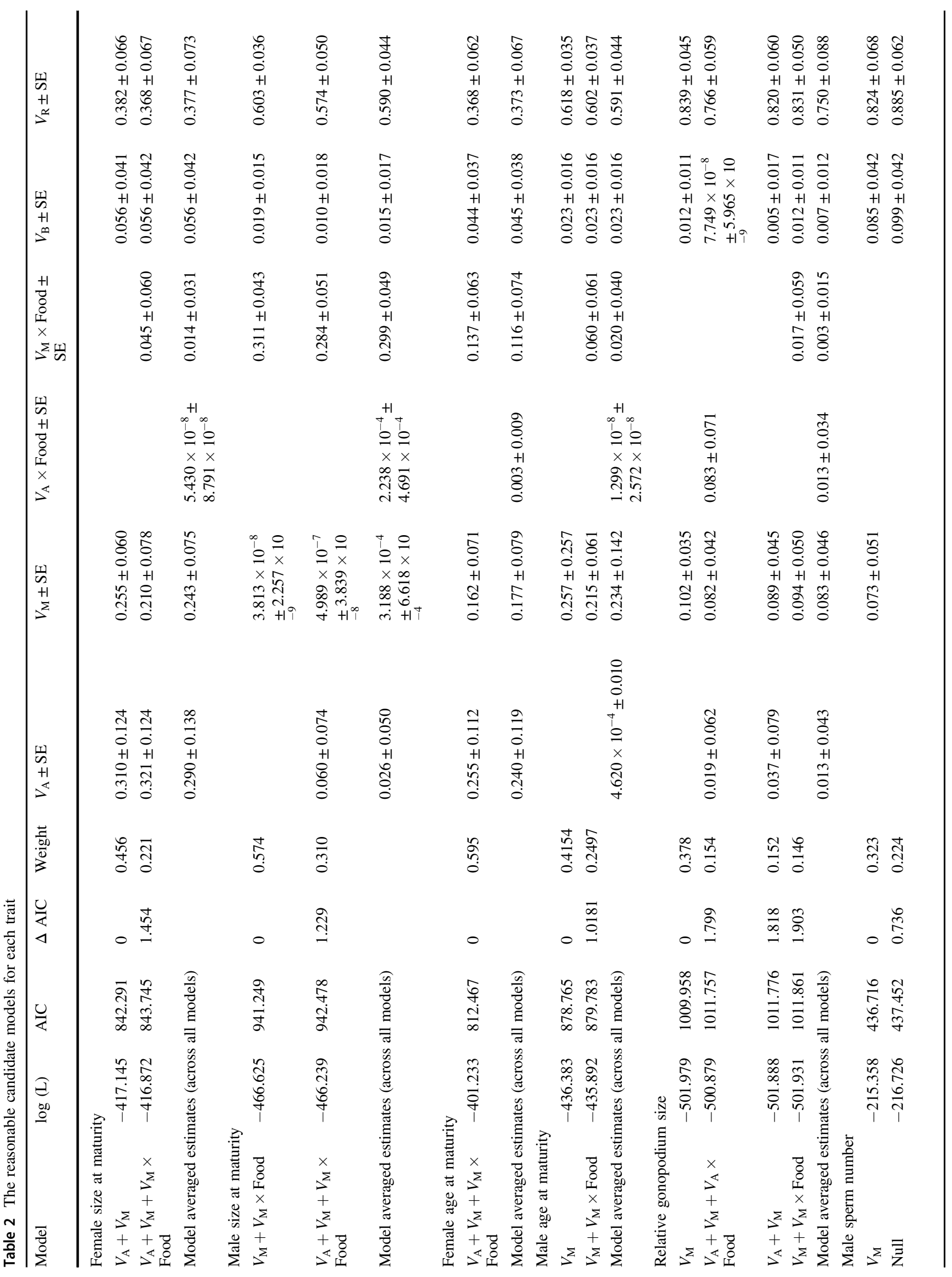




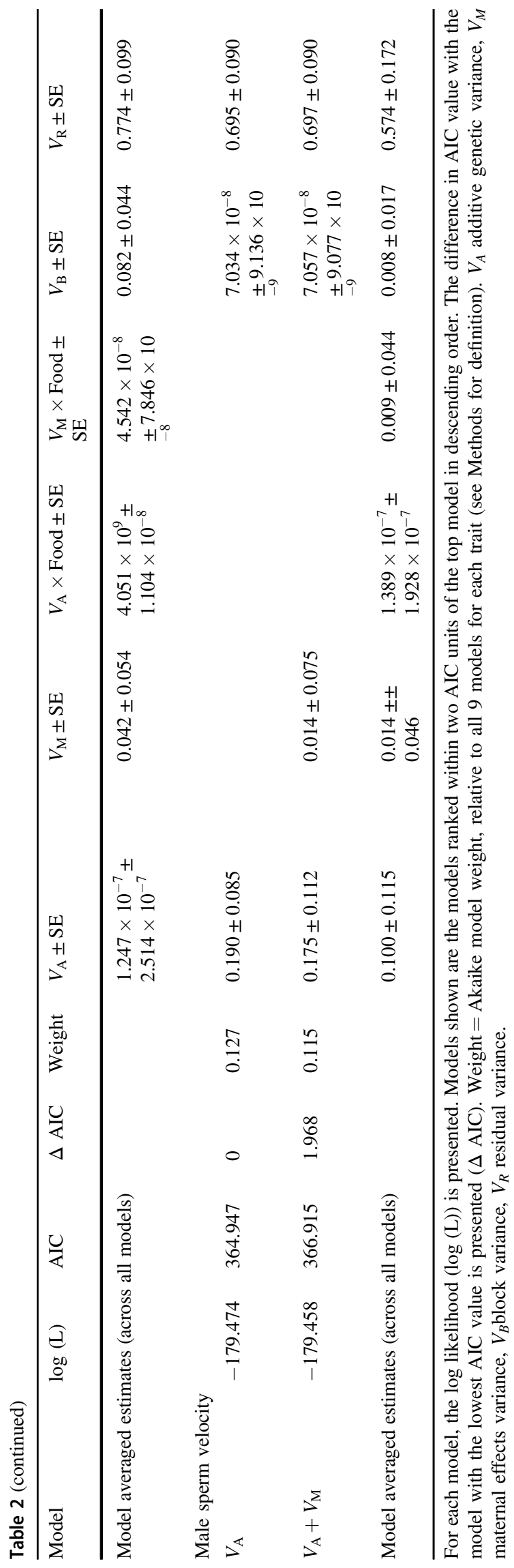

with just $V_{\mathrm{A}}+V_{\mathrm{M}}$, the heritability and the strength of maternal effects were both relatively low, though the latter accounted for nearly $10 \%$ of the phenotypic variation and was statistically significant (Table 1). The top model contained only $V_{\mathrm{M}}$. Although models containing both $V_{\mathrm{A}} \times$ Food and $V_{\mathrm{M}} \times$ Food interactions were included in the reasonable candidate model set, neither parameter estimates differed significantly from zero (LRT: $V_{\mathrm{A}} \times$ Food: $X^{2}{ }_{(1)}=$ 2.019, $P=0.364 ; \quad V_{\mathrm{M}} \times$ Food: $X_{(1)}^{2}=0.097, \quad P=0.953$; Table 2).

\section{Sperm traits}

Males in the control treatment had sperm with a faster mean velocity, but there was no difference between food treatments in mean sperm number (Table 1; Fig. S1). For sperm number, the top model contained only maternal effects variance $V_{\mathrm{M}}$, and heritability was negligible (Table 2). However, the estimate of $V_{\mathrm{M}}$ in the top model had a large SE and was not significant (LRT: $X^{2}{ }_{(1)}=2.736, P=0.098$ ) and the null model with only fixed and block effects was also a 'reasonable candidate' model (Table 2). For sperm velocity, the top model contained only $V_{\mathrm{A}}$, with a corresponding significant heritability of 0.215 (0.092 SE), (LRT: $\left.X^{2}{ }_{(1)}=4.715, P=0.029\right)$, but if we considered the 'basic' model with $V_{\mathrm{A}}+V_{\mathrm{M}}$, the estimate of heritability was reduced to 0.197 (0.125 SE; Table 1) and was nonsignificant $\left(\mathrm{LRT}: X_{(1)}^{2}=2.073, P=0.149\right)$.

\section{Discussion}

Understanding the causes of phenotypic variation in traits is fundamental to predicting evolutionary responses. Our study of life history and sexual traits in the mosquitofish Gambusia holbrooki revealed several patterns. First, we found sex differences in heritabilities: there were significant heritability estimates for female age and size at maturity, but not for the male traits examined. Second, in both sexes there were maternal effects that persisted until sexual maturity for all traits except the sperm traits (i.e. for five of seven traits). Third, there were interactions between maternal effects variance and food treatment for female age at maturity and male size at maturity. Failure to account for maternal by environmental interactions $(\mathrm{M} \times \mathrm{E})$ led to overestimates of genotype-by-environment interactions $(\mathrm{G} \times \mathrm{E})$. We discuss each of these points below.

The relative importance of heritable genetic effects in our study differed between males and females: in general, female traits had higher heritability. Because of the lack of genetic variance in males, we did not attempt to estimate cross-sex genetic correlations, but our results indicate a very different underlying genetic architecture shaping female and 
a

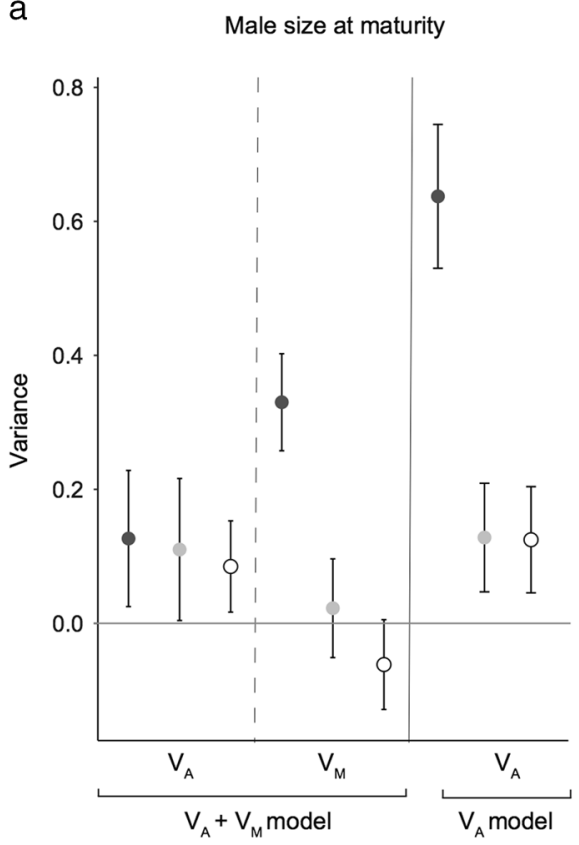

Fig. 2 Effect of food treatment on variance components for a male size at maturity; $\mathbf{b}$ female age at maturity: additive genetic effects $\left(V_{\mathrm{A}}\right)$ and maternal effects variance $\left(V_{\mathrm{M}}\right) \pm \mathrm{SE}$ for a bivariate model with $V_{\mathrm{A}}+$ $V_{\mathrm{M}}+V_{\mathrm{B}}+V_{\mathrm{R}}$, and $V_{\mathrm{A}}$ only $\left(+V_{\mathrm{B}}+V_{\mathrm{R}}\right.$; see Methods for details). Dark

Table 3 Variance-covariance matrices from the bivariate models of traits expressed in each environment for female age at maturity and male size at maturity

\begin{tabular}{llllll}
\hline \multicolumn{2}{c}{ Female age at maturity } & & \multicolumn{2}{l}{ Male size at maturity } \\
\cline { 2 - 3 } \cline { 5 - 6 } & Control & Low food & & Control & Low food \\
\hline$V_{\mathrm{A}}$ & $0.212(0.122)$ & $0.800(0.699)$ & & $0.127(0.102)$ & $0.719(0.644)$ \\
& $0.204(0.160)$ & $0.307(0.418)$ & & $0.085(0.068)$ & $0.110(0.106)$ \\
$V_{\mathrm{M}}$ & $0.222(0.060)$ & $0.711(0.256)$ & & $0.330(0.072)$ & $-0.712(1.378)$ \\
& $0.256(0.097)$ & $0.585(0.199)$ & $-0.062(0.067)$ & $0.023(0.074)$ \\
$V_{\mathrm{B}}$ & $0.049(0.036)$ & $0.989(0.776)$ & - & - \\
& $0.071(0.055)$ & $0.106(0.161)$ & - & - \\
$V_{\mathrm{R}}$ & $0.363(0.066)$ & - & $0.570(0.063)$ & - \\
& - & $0.418(0.232)$ & - & $0.437(0.087)$ \\
\hline
\end{tabular}

Variances of the parameters for each of the food treatments are shown on the diagonals (shaded), covariances below diagonal (in italics), and correlations above. All SEs are shown in brackets. $V_{A}$ additive genetic variance, $V_{M}$ maternal effects variance, $V_{B}$ block variance (only fitted for female age at maturity due to lack of convergence for male size at maturity), $V_{R}$ residual variance. Trait values were standardised to unit variance prior to analyses (see Methods for details).

male phenotypes. This is in contrast to estimates in many other taxa of strong cross-sex correlations in morphology (Kruuk et al. 2008; Poissant et al. 2010), and maturation time (e.g. Guntrip et al. et al. 1997). The differences between the sexes we observed here could potentially be due to the biology of mosquitofish. Females have indeterminate growth and their fecundity increases with body

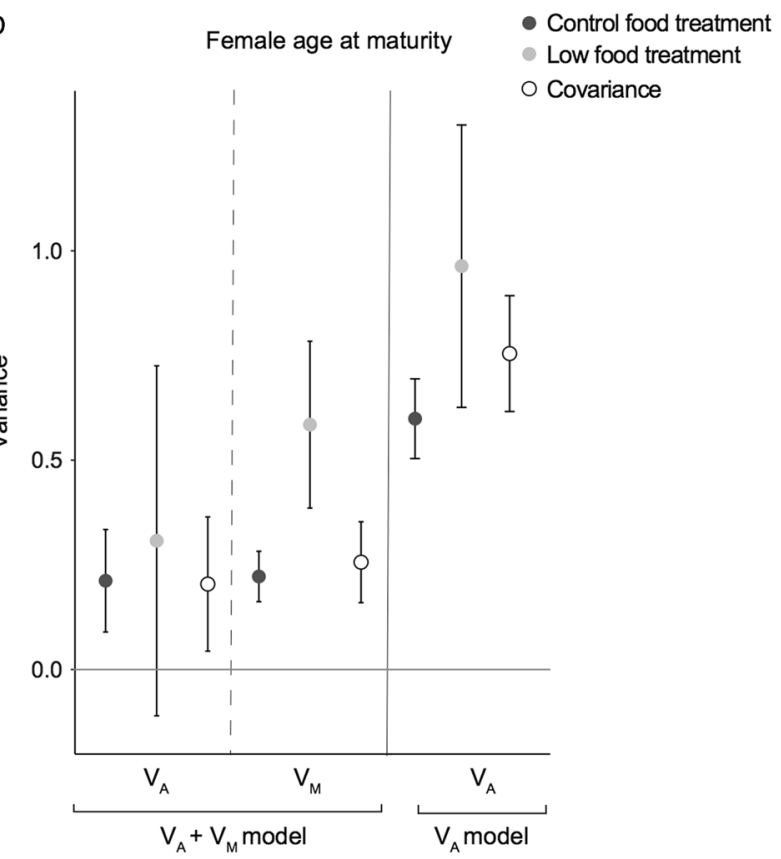

symbols represent values for fish in the control food treatment, light symbols represent values for fish in the low food treatment, and white symbols represent the covariance between the traits in the two treatments

size (Bisazza et al. 1989; Callander et al. 2012), while males stop growing upon maturation. Selection pressures on growth and maturation rates are thus likely to be highly sexspecific. Sex differences in heritability of traits might be due to sexual selection acting more strongly on males, thereby depleting the amount of additive genetic variation expressed in males (Van Homrigh et al. 2007). Lower heritability of female traits has also been found in other species, for example for morphological traits in house sparrows (Jensen et al. 2003). However, the implications for evolutionary dynamics of differences in heritability between the sexes still remain relatively underexplored.

Within males, the relative importance of heritable genetic effects also differed among sexual traits. There was a low, non-significant heritability for relative gonopodium size $(0.039 \pm 0.083 \mathrm{SE}$; Table 1$)$. Interestingly, this is similar to an estimate of realised heritability based on artificial selection on relative gonopodium length in the same study population $(0.028 \pm 0.006 \mathrm{SE}$, Booksmythe et al. 2016) - a reminder that a response to selection is possible even when heritability is low. Sperm number showed no evidence of additive genetic variance, but sperm velocity did. The low heritability of sperm number may indicate that sperm quantity is highly condition-dependent (e.g. influenced by diet; see O'Dea et al. 2014). Sperm velocity showed significant heritability in the 'top' model (Table 2), which could potentially fit with Y-linked effects as suggested in other poecilids (e.g. Evans 2011). We note however that the 
estimate was lower and not significant in the basic model with maternal effects (Table 1), so there was no strong support for significant heritability of sperm velocity across all models.

Maternal effects contributed to trait variance for both males and females. Female mosquitofish invest in their offspring prior to fertilisation by provisioning eggs (lecithotrophy; Fernández-Delgado and Rossomanno 1997; Pollux et al. 2014) and also possibly via subsequent nutrient transfer to embryos (see Marsh-Matthews et al. 2005; Marsh-Matthews et al. 2010). Our results suggest that differences between mothers in their prenatal allocation of resources to either eggs or embryos have important implications for their offspring's subsequent development: maternal effects were still apparent in traits measured at sexual maturity (see also Kruuk et al. 2015). Further, in addition to the overall presence of maternal effects, we observed significant maternal-by-environmental variance $(\mathrm{M} \times \mathrm{E})$ interactions for female age at maturity and male size at maturity. These interactions were apparent even though the food treatment was applied after maternal provisioning ended. They indicate that studies of maternal effects need to consider the potential impact of environmental heterogeneity: here, we would have reached a very different conclusion as to the importance of maternal effects had we only considered offspring reared under 'control' rather than 'low food' conditions. We found a significant positive covariance of the maternal effects across environments for female age at maturity. That is, mothers with maternal effects that caused their daughters to take longer to mature in the control environment also had daughters that took longer to mature in the low food environment (Fig. 2, Table 3). For males, however, there was no support for covariance across the food treatments for maternal effects on male size - probably due to the very low maternal effects variance expressed in the low food environment. We therefore found no evidence for trade-offs in maternal effects across environments. Similarly, Charmantier and Garant (2005) also find little evidence of genetic trade-offs via negative cross-environment genetic correlations, also suggesting that the role of environmental heterogeneity in generating life-history trade-offs remains unclear (see also discussion in Kruuk et al. 2008). As a final point, as noted in the Methods, our estimates of maternal effects variance could be inflated by dominance genetic variance and the separation of the two is a challenging issue for many studies (Wolak and Keller 2014). Data from different systems indicate that dominance genetic variance itself is typically small relative to additive genetic variance (Hill et al. 2008; Wolak and Keller 2014; Zhu et al. 2015). There is nevertheless the possibility that our estimates of $\mathrm{M} \times \mathrm{E}$ are inflated by dominance genetic-by-environment $(\mathrm{D} \times \mathrm{E})$ interactions. There are examples of changes in non-additive genetic variance across environments in some taxa (e.g. Blows and Sokolowski 1995; Chirgwin et al. 2017; Kumar et al. 2015), but in general evidence for $\mathrm{D} \times \mathrm{E}$ appears to be markedly less prevalent than for $\mathrm{G} \times \mathrm{E}$. We note also that, in turn, estimates of dominance variance in other systems may be inflated by maternal or shared environment effects if these are not properly modelled.

We found striking differences in our results from models incorporating maternal effects and maternal-byenvironmental variances $(\mathrm{M} \times \mathrm{E})$ compared to those without. Estimates of the variance due to additive genetic effects $\left(V_{\mathrm{A}}\right)$ were always higher in models where $V_{\mathrm{M}}$ was not estimated, indicating that ignoring maternal effects inflated estimates of $V_{\mathrm{A}}$ (Table S1). Similarly, when we compared estimates of $V_{\mathrm{A}} \times$ Food (i.e. $\mathrm{G} \times \mathrm{E}$ ) from models without and with $V_{\mathrm{M}} \times$ Food (i.e. $\mathrm{M} \times \mathrm{E}$ ), we found larger estimates if $V_{\mathrm{M}} \times$ Food was not accounted for. For instance, for female age at maturity, $V_{\mathrm{A}} \times$ Food was estimated at $0.054 \pm 0.065$ in the model with $V_{\mathrm{A}}+V_{\mathrm{M}}+V_{\mathrm{A}} \times$ Food, but as $4 \times 10^{-8} \pm$ $6 \times 10^{-9} \mathrm{SE}$ in the model with $V_{\mathrm{A}}+V_{\mathrm{M}}+V_{\mathrm{A}} \times$ Food + $V_{\mathrm{M}} \times$ Food. Similarly, for male size at maturity, the model of $V_{\mathrm{A}}+V_{\mathrm{M}}+V_{\mathrm{A}} \times$ Food returned a $\mathrm{G} \times \mathrm{E}$ interaction estimate of $0.172 \pm 0.078 \mathrm{SE}$, but the model $V_{\mathrm{A}}+V_{\mathrm{M}}+V_{\mathrm{A}} \times$ Food $+V_{\mathrm{M}} \times$ Food provided an estimate of $4 \times 10^{-7} \pm 4 \times 10^{-8}$ SE. The right-hand panels in Fig. 2 also show the much greater change in estimates of $V_{\mathrm{A}}$ across environments in models fitted without maternal effects. Although this is unsurprising, studies of genotype-by-environment interactions rarely also account for maternal-by-environment interactions. It is well established that the presence of maternal effects (or other non-additive causes of covariance between relatives, such as dominance variance) can inflate heritability estimates if not accounted for properly (Falconer and Mackay 1996; Kruuk and Hadfield 2007). In the same vein, our results indicate that estimates of $G \times E$ can be inflated by the existence of unaccounted-for $\mathrm{M} \times \mathrm{E}$ interactions. It is thus possible that previous studies of other populations have overestimated the role of $\mathrm{G} \times \mathrm{E}$ in driving phenotypic variation in systems where maternal effects (or other causes of increased similarity between relatives such as non-additive genetic effects) are important.

In sum, our study found sex differences in the genetic architecture underlying important phenotypic traits. Additionally, it suggests that maternal effects can shape phenotypic traits even when there is no postnatal investment and, furthermore, that differences between offspring of different mothers can interact with the offspring's rearing environment to influence their adult phenotypes. Our findings also illustrate the need to consider maternal-by-environmental interactions in quantitative genetic studies. $G \times$ Es have been well studied and there is increasing appreciation of their potential importance in evolutionary ecology (e.g. reviews by Des Marais et al. 2013; Hunt and Hosken 2014, respectively). Our 
analysis here illustrates the need to also consider other potential contributors to environmental interactions when assessing $\mathrm{G} \times \mathrm{E}$ interactions, as failure to do so could result in an overestimation of the importance of $\mathrm{G} \times \mathrm{E}$. Including $\mathrm{M} \times \mathrm{E}$ interactions may thus improve our understanding of the factors that contribute to phenotypic variance in different components of individuals' life histories.

\section{Data archiving}

Data available from Dryad: https://doi.org/10.5061/dryad. 9s1gm

Acknowledgements We thank the Australian National University Animal Services team for fish maintenance, three referees for their comments on the manuscript and Matt Wolak and Bill Hill for useful discussion on the prevalence of dominance-environment interactions. Animal use permit: ANU AEEC protocol A2011/64.

Funding The study was financially supported by the Australian Research Council (DP160100285) to M.D.J. R.V.T. was supported by fellowships from Consejo Nacional de Ciencia y Tecnología-México and the Australian National University's Research School of Biology. L.E.B.K. was supported by an Australian Research Council Future Fellowship (FT110100453).

\section{Compliance with ethical standards}

Conflict of interest The authors declare that they have no competing interests.

\section{References}

Abramoff, M.D., Magelhaes, P.J. \& Ram, S.J. (2004) Image processing with ImageJ. Biophotonics International 11: 36-42

Arnold TW (2010) Uninformative parameters and model selection using Akaike's Information Criterion. J Wildl Manag 74 (6): $1175-1178$

Barton NH, Turelli M (1989) Evolutionary quantitative genetics: how little do we know? Annu Rev Genet 23(1):337-370

Bisazza A, Marconato A, Marin G (1989) Male mate preferences in the mosquitofish Gambusia holbrooki. Ethology 83:335e 343

Bisazza A, Marin G (1991) Male size and female mate choice in the eastern mosquitofish (Gambusia holbrooki, Poeciliidae). Copeia 3:730-735

Blows MW, Sokolowski MB (1995) The expression of additive and nonadditive genetic variation under stress. Genetics 140 (3):1149-1159

Booksmythe I, Head ML, Keogh JS, Jennions MD (2016) Fitness consequences of artificial selection on relative male genital size. Nat Commun 7:11597

Burnham KP, Anderson D (2002) Model selection and multimodel inference: a practical information-theoretic approach. Springer Science \& Business Media, New York, USA

Butler DG, Cullis BR, Gilmour AR, Gogel BJ (2009) ASReml-R reference manual, release 3: Brisbane, Qld

Callander S, Backwell PRY, Jennions MD (2012) Context-dependent male mate choice: the effects of competitor presence and competitor size. Behav Ecol 23(2):355-360
Charmantier A, Garant D (2005) Environmental quality and evolutionary potential: lessons from wild populations. P Roy Soc BBiol Sci 272(1571):1415-1425

Chirgwin E, Marshall DJ, Sgrò CM, Monro K (2017) The other 96\%: Can neglected sources of fitness variation offer new insights into adaptation to global change? Evolut Appl 10(3):267-275

de Leon N, Jannink J-L, Edwards JW, Kaeppler SM (2016) Introduction to a special issue on genotype by environment interaction. Crop Sci 56(5):2081-2089

Des Marais DL, Hernandez KM, Juenger TE (2013) Genotype-byenvironment interaction and plasticity: exploring genomic responses of plants to the abiotic environment. Annu Rev Ecol Syst 44:5-29

Donohue K, Pyle EH, Messiqua D, Heschel MS, Schmitt J (2000) Density dependence and population differentiation of genetic architecture in Impatiens capensis in natural environments. Evolution 54(6):1969-1981

Evans JP (2011) Patterns of genetic variation and covariation in ejaculate traits reveal potential evolutionary constraints in guppies. Heredity 106(5):869-875

Evans JP, Rahman MM, Gasparini C (2015) Genotype-byenvironment interactions underlie the expression of pre- and post-copulatory sexually selected traits in guppies. J Evol Biol 28 (4):959-972

Falconer DS, Mackay TFC (1996) Introduction to Quantitative Genetics. Longman, Harlow, UK

Ferguson HM, Read AF (2002) Genetic and environmental determinants of malaria parasite virulence in mosquitoes. Proc Biol Sci 269(1497):1217-1224

Fernández-Delgado C, Rossomanno S (1997) Reproductive biology of the mosquitofish in a permanent natural lagoon in south-west Spain: two tactics for one species. J Fish Biol 51(1):80-92

Guntrip J, Sibly RM, Holloway GJ (1997) The effect of novel environment and sex on the additive genetic variation and covariation in and between emergence body weight and development period in the cowpea weevil, Callosobruchus maculatus (Coleoptera, Bruchidae). Heredity 78(2):158-165

Head ML, Kahn AT, Henshaw JM, Keogh JS, Jennions MD (2017) Sexual selection on male body size, genital length and heterozygosity: consistency across habitats and social settings. J Anim Ecol.

Hill WG, Goddard ME, Visscher PM (2008) Data and theory point to mainly additive genetic variance for complex traits. PLoS Genet 4 (2):e1000008

Hoffmann AA, Merila J (1999) Heritable variation and evolution under favourable and unfavourable conditions. Trends Ecol Evol 14(3):96-101

Horth L, Binckley C, Wilk R, Reddy P, Reddy A (2010) Color, body size, and genitalia size are correlated traits in eastern mosquitofish (Gambusia holbrooki). Copeia 2:196-202

Houle D (1992) Comparing evolvability and variability of quantitative traits. Genetics 130(1):195

Hunt J, Hosken DJ (2014) Genotype-by-environment interactions and sexual selection. John Wiley \& Sons, Vancouver

Jensen H, Sæther BE, Ringsby TH, Tufto J, Griffith SC, Ellegren H (2003) Sexual variation in heritability and genetic correlations of morphological traits in house sparrow (Passer domesticus). J Evol Biol 16(6):1296-1307

Jia F-Y, Greenfield MD, Collins RD (2000) Genetic variance of sexually selected traits in waxmoths: maintenance by genotype $\times$ environment interaction. Evolution 54(3):953-967

Johnson T, Barton N (2005) Theoretical models of selection and mutation on quantitative traits. Philos Trans R Soc Lond B Biol Sci 360(1459):1411 
Kruuk LE, Clutton-Brock TH, Slate J, Pemberton JM, Brotherstone S, Guinness FE (2000) Heritability of fitness in a wild mammal population. Proc Natl Acad Sci USA 97(2):698-703

Kruuk LEB, Hadfield JD (2007) How to separate genetic and environmental causes of similarity between relatives. J Evol Biol 20 (5):1890-1903

Kruuk LEB, Livingston J, Kahn A, Jennions MD (2015) Sex-specific maternal effects in a viviparous fish. Biol Lett 11(8):20150472

Kruuk LEB, Slate J, Wilson AJ (2008) New answers for old questions: the evolutionary quantitative genetics of wild animal populations. Annu Rev Ecol Syst 39:525-548

Kumar S, Molloy C, Muñoz P, Daetwyler H, Chagné D, Volz R (2015) Genome-enabled estimates of additive and nonadditive genetic variances and prediction of apple phenotypes across environments. G3: Genes|Genomes|Genet 5(12):2711-2718

Laugen AT, Kruuk LEB, Laurila A, RÄSÄNen K, Stone J, MerilÄ J (2005) Quantitative genetics of larval life-history traits in Rana temporaria in different environmental conditions. Genet Res 86 (3):161-170

Livingston JD, Kahn AT, Jennions MD (2014) Sex differences in compensatory and catch-up growth in the mosquitofish Gambusia holbrooki. Evol Ecol 28(4):687-706

Lock JE, Smiseth PT, Moore PJ, Moore AJ (2007) Coadaptation of prenatal and postnatal maternal effects. Am Nat 170(5):709-718

Lynch M, Walsh B (1998). Genetics and analysis of quantitative traits: Sunderland, MA, USA

Marsh-Matthews E, Brooks M, Deaton R, Tan H (2005) Effects of maternal and embryo characteristics on post-fertilization provisioning in fishes of the genus Gambusia. Oecologia 144(1):12-24

Marsh-Matthews E, Deaton R, Brooks M (2010) Survey of matrotrophy in lecithotrophic poeciliids. In: Uribe MC, Grier HJ (eds) Viviparous fishes II, the proceedings of the III international symposium on viviparous fishes. New Life Publications, Homestead, FL, pp 255-258

Marshall DJ, Uller T (2007) When is a maternal effect adaptive? Oikos 116(12):1957-1963

McAdam AG, Boutin S, Réale D, Berteaux D (2002) Maternal effects and the potential for evolution in a natural population of animals. Evolution 56(4):846-851

McAdam AG, Garant D, Wilson AJ (2014) The effects of others' genes: maternal and other indirect genetic effects. In: Charmantier A, Garant D and Kruuk LEB (eds) Quantitative genetics in the wild. Oxford University Press, pp 84-103

Mousseau TA, Fox CW (1998) The adaptive significance of maternal effects. Trends Ecol Evol 13(10):403-407

Noble DWA, McFarlane SE, Keogh JS, Whiting MJ (2014) Maternal and additive genetic effects contribute to variation in offspring traits in a lizard. Behav Ecol 25(3):633-640

O'Dea RE, Jennions MD, Head ML (2014) Male body size and condition affects sperm number and production rates in mosquitofish. Gambusia holbrooki J Evol Biol 27(12):2739-2744

Parker GA, Pizzari T (2010) Sperm competition and ejaculate economics. Biol Rev 85(4):897-934

Parker TH, Garant D (2004) Quantitative genetics of sexually dimorphic traits and capture of genetic variance by a sexuallyselected condition-dependent ornament in red junglefowl (Gallus gallus). J Evol Biol 17(6):1277-1285

Pick JL, Ebneter C, Hutter P, Tschirren B (2016) Disentangling genetic and prenatal maternal effects on offspring size and survival. Am Nat 188(6):628-639

Pilastro A, Giacomello E, Bisazza A (1997) Sexual selection for small size in male mosquitofish (Gambusia holbrooki). P Roy Soc B Biol Sci 264(1385):1125-1129

Poissant J, Wilson AJ, Coltman DW (2010) Sex-specific genetic variance and the evolution of sexual dimorphism: a systematic review of cross-sex genetic correlations. Evolution 64(1):97-107
Pollux BJA, Meredith RW, Springer MS, Reznick DN (2014) The evolution of the placenta drives a shift in sexual selection in livebearing fish. Nature 513:233-236

Postma E (2014) Four decades of estimating heritabilities in wild vertebrate populations: improved methods, more data, better estimates. In: Charmantier A, Garant D and Kruuk LEB (eds) Quantitative genetics in the wild. Oxford University Press, Oxford, UK, pp 16-33

Pyke GH (2005) A Review of the biology of Gambusia affinis and $G$. holbrooki. Rev Fish Biol Fish 15(4):339-365

Räsänen K, Kruuk LEB (2007) Maternal effects and evolution at ecological time-scales. Funct Ecol 21(3):408-421

Reznick D, Yang AP (1993) The influence of fluctuating resources on life-history - patterns of allocation and plasticity in female guppies. Ecology 74(7):2011-2019

Roff DA (1992) The evolution of life histories. Chapman and Hall, New York, USA

Roff DA, Mousseau TA (1987) Quantitative genetics and fitness: lessons from Drosophila. Heredity 58(1):103-118

Rowiński PK, Rogell B (2017) Environmental stress correlates with increases in both genetic and residual variances: a meta-analysis of animal studies. Evolution 71(5):1339-1351

Saastamoinen M, Brommer JE, Brakefield PM, Zwaan BJ (2013) Quantitative genetic analysis of responses to larval food limitation in a polyphenic butterfly indicates environment- and traitspecific effects. Ecol Evol 3(10):3576-3589

Sgrò CM, Hoffmann AA (2004) Genetic correlations, tradeoffs and environmental variation. Heredity 93(3):241-248

Simmons LW, Wernham J, García-González F, Kamien D (2003) Variation in paternity in the field cricket Teleogryllus oceanicus: no detectable influence of sperm numbers or sperm length. Behav Ecol 14(4):539-545

Stearns SC (1983) The evolution of life-history traits in mosquitofish since their introduction to Hawaii in 1905 - rates of evolution, heritabilities, and developmental plasticity. Am Zool 23(1):65-75

Symonds MRE, Moussalli A (2011) A brief guide to model selection, multimodel inference and model averaging in behavioural ecology using Akaike's information criterion. Behav Ecol Sociobiol 65(1):13-21

Trivers RL (1974) Parent-offspring conflict. Am Zool 14(1):249-264

Uller T, Nakagawa S, English S (2013) Weak evidence for anticipatory parental effects in plants and animals. J Evol Biol 26 (10):2161-2170

Van Homrigh A, Higgie M, McGuigan K, Blows MW (2007) The depletion of genetic variance by sexual selection. Curr Biol 17 (6):528-532

Vega-Trejo R, Head ML, Jennions MD (2015) Evidence for inbreeding depression in a species with limited opportunity for maternal effects. Ecol Evol 5(7):1398-1404

Vega-Trejo R, Head ML, Jennions MD (2016a) Inbreeding depression does not increase after exposure to a stressful environment: a test using compensatory growth. BMC Evol Biol 16(1):68

Vega-Trejo R, Head ML, Keogh JS, Jennions MD (2017) Experimental evidence for sexual selection against inbred males. J Anim Ecol 86(2):394-404

Vega-Trejo R, Jennions MD, Head ML (2016b) Are sexually selected traits affected by a poor environment early in life? BMC Evol Biol 16(1):263

Vieira C, Pasyukova EG, Zeng ZB, Hackett JB, Lyman RF, Mackay TFC (2000) Genotype-environment interaction for quantitative trait loci affecting life span in Drosophila melanogaster. Genetics 154(1):213-227

Wilson AJ, Coltman DW, Pemberton JM, Overall ADJ, Byrne KA, Kruuk LEB (2005) Maternal genetic effects set the potential for evolution in a free-living vertebrate population. J Evol Biol 18 (2):405-414 
Wilson AJ, Reale D, Clements MN, Morrissey MM, Postma E, Walling CA et al (2010) An ecologist's guide to the animal model. J Anim Ecol 79(1):13-26

Wolak ME, Keller LF (2014) Dominance genetic variance and inbreeding in natural populations. In: Charmantier A, Garant D, Kruuk LEB (eds) Quantitative genetics in the wild. Oxford University Press, Oxford, p 104-128

Wolf JB, Leamy LJ, Roseman CC, Cheverud JM (2011) Disentangling prenatal and postnatal maternal genetic effects reveals persistent prenatal effects on offspring growth in mice. Genetics 189 (3):1069-1082

Wolf JB, Wade MJ (2009) What are maternal effects (and what are they not)? Philos Trans R Soc Lond B Biol Sci 364 (1520):1107-1115
Wolf JB, Wade MJ (2016) Evolutionary genetics of maternal effects. Evolution 70(4):827-839

Wood CW, Brodie ED (2015) Environmental effects on the structure of the G-matrix. Evolution 69(11):2927-2940

Zhu Z, Bakshi A, Vinkhuyzen AA, Hemani G, Lee SH, Nolte IM et al. (2015) Dominance genetic variation contributes little to the missing heritability for human complex traits. Am J Hum Genet 96(3):377-385

Zulian E, Bisazza A, Marin G (1993) Determinants of size in male eastern mosquitofish (Gambusia holbrooki)—inheritance and plasticity of a sexual selected character. Boll Zool 60 (3):317-322 